\title{
The Kinematic Alignment Technique for Total Knee Arthroplasty
}

\author{
Charles Rivière, Ciara Harman, Oliver Boughton, \\ and Justin Cobb
}

\section{Key Points}

- Kinematic alignment (KA) is a relatively new surgical technique for implanting total knee components.

- The vast majority of patients are eligible for a kinematic implantation, and this may be achieved with most primary implant designs.

- Kinematically aligning the femoral component is relatively easy and straightforward; following this first step, the kinematic tibial implant positioning is made reproducible by a combination of measured resection and ligament referencing techniques. As the surgical technique is not demanding and complex cases are rare, the KA technique is overall reliable.

- KA implantation results in high prosthetic joint function, in a large range of

C. Rivière $(\bowtie)$

South West London Elective Orthopaedic Centre,

Epsom, UK

The MSK Lab-Imperial College London,

White City Campus, London, UK

\section{Harman}

South West London Elective Orthopaedic Centre,

Epsom, UK

O. Boughton · J. Cobb

The MSK Lab-Imperial College London,

White City Campus, London, UK

e-mail: o.boughton@imperial.ac.uk;

j.cobb@imperial.ac.uk preoperative deformity, and whether the postoperative alignment of the tibial component, knee and limb is in the varus and valgus outlier range of mechanical alignment criteria.

- Due to an improvement in knee biomechanics, it is expected that component lifespan will also be improved. A prospective study of 222 successive unselected KATKAs has reported excellent implant survival at 10 -year followup. Nevertheless, long-term outcomes of KA patients still need to be defined.

- In the event of severe constitutional limb deformity, kinematic component positioning may be adjusted in order to reduce the limb deformity and hopefully improve prosthetic biomechanics. This defines the restricted kinematic alignment concept.

- Development of new implant designs adapted to KA implantation needs to be undertaken.

\subsection{Introduction}

\subsubsection{What Is It? The Concept}

The kinematic alignment technique (KA) for total knee arthroplasty (TKA) is a surgical technique recently developed that aims to anatomically position and kinematically align total knee 
components [1]. The kinematic implantation aims to resurface the knee joint by removing a cartilage and bone thickness equivalent to the implant thickness and where the knee implants are aligned on the knee kinematic axes that dictate motion of the patella and tibia around the distal femoral epiphysis [2-4]. Similar to unicompartmental knee replacement, kinematically aligning total knee components restores the constitutional knee joint line orientation and the physiological knee laxity without the need for soft-tissue release [5] (Fig. 16.1).

\subsubsection{Why Has This New Surgical Technique Been Developed? The Rationale}

The KA technique for TKA has been developed following the observations that mechanically aligned (MA) TKAs are affected by residual complications that have not been solved by technology, and the rationale for the MA technique is being challenged.

MA-TKAs are affected by residual complications that have not been solved by technology [6-10], thus suggesting intrinsic technical limitations. The proportion of residual knee symptoms (e.g. pain, instability, effusion) and patient dissatisfaction after MA-TKA has been reported to be as high as $50 \%$ and $20 \%$, respectively [6-10]. Interestingly, neither the multiple modern TKA designs nor the many technological assistive devices (e.g. computer assistance, robotics, personalized instrumentation) have solved the issues [6-10]. The mechanical alignment technique is a technically challenging [11-13], systematic technique of implantation [5] that generates nonphysiological prosthetic knee anatomy $[5,11$, 14], balance [11, 15] and biomechanics [16-18]. Aiming at a similar component implantation alignment goal, it does not recreate the high variability in knee anatomy [14, 19] and laxity [20] between individuals. This may be responsible for
Constitutional alignment
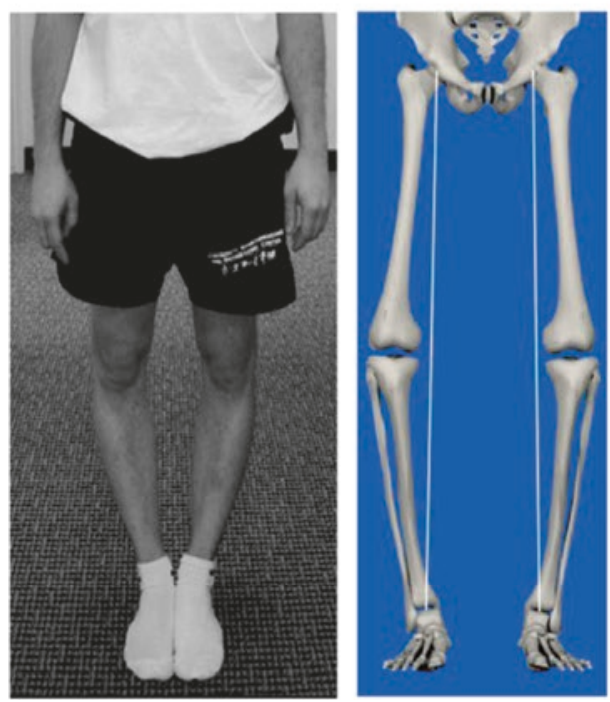

Patient-specific Alignment techniques UKA KA

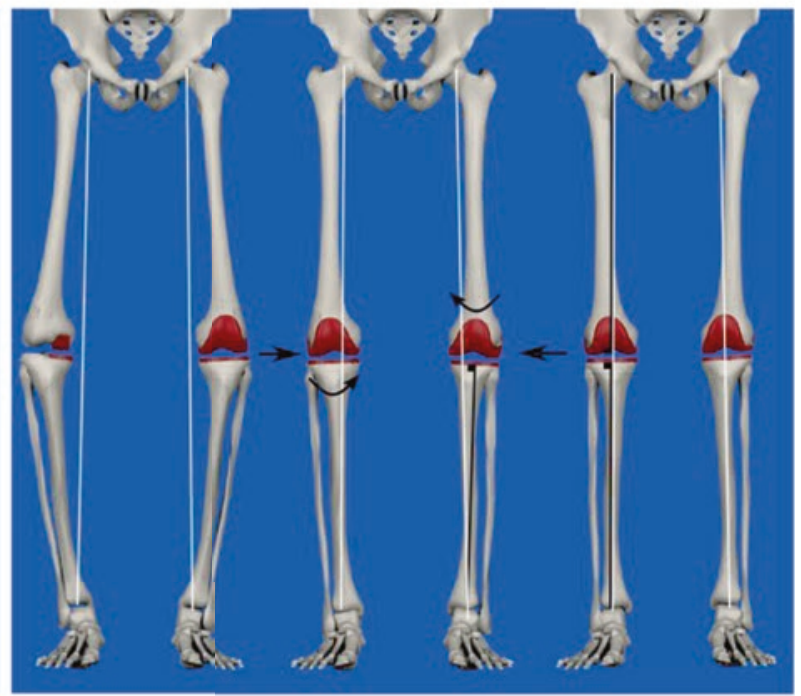

Fig. 16.1 The multiple philosophies for aligning knee components. Mechanical alignment (MA) and kinematic alignment (KA) are two different techniques for positioning knee components. MA and KA may have their component positioning adjusted in order to generate a more physiological (adjusted MA, aMA) or biomechanically sound (restricted KA, rKA) prosthetic knee. Only the unicompartmental knee replacement (UKA), KA and rKA are personalized techniques for implanting knee components 
non-physiological knee ligament laxities and residual instability $[10,11,15]$ and abnormal knee kinematics $[13,16,17]$. To illustrate these points, the MA technique was linked to:

1. Frequent prosthetic overstuffing of the distal lateral femoral condyle [11] which leads to abnormal stretching of the lateral retinaculum ligament during knee flexion.

2. Frequent, uncorrectable collateral ligament imbalance when performed with a measured resection technique (approximately 40\% imbalance $\geq 2 \mathrm{~mm}$ ) $[11,12]$ or gap-balancing (knee flexion gap tighter than physiological) [15] techniques.

\section{The rational of mechanically positioning knee implants is being challenged:}

- The first pillar of the MA technique is to align knee components systematically, perpendicular to femoral and tibial mechanical axes. In fact, a bulk of evidence now suggests that knee kinematics is dictated by three main axes (Fig. 16.2) [2], and the cylindrical (or transcondylar) axis is the one upon which the tibia effectively rotates around the femur from $10^{\circ}$ to $120^{\circ}$ of knee flexion [4].
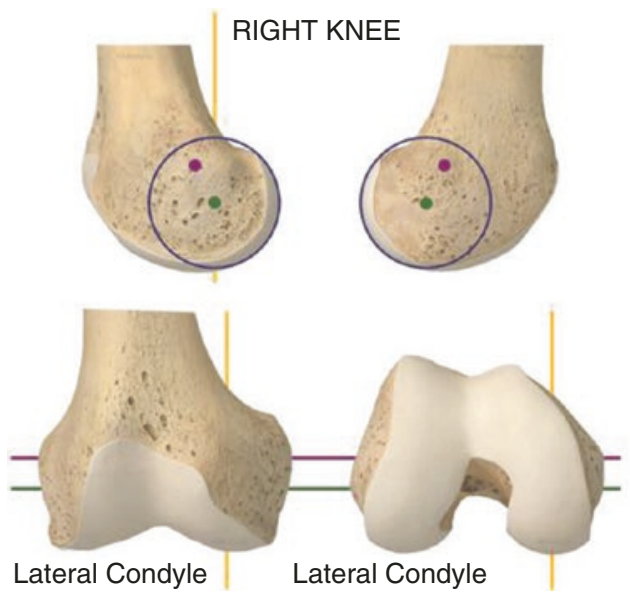

Fig. 16.2 Kinematically implanted knee components are aligned on the three main knee kinematics axes, which dictate physiological knee motion. This is achieved by anatomically positioning knee components or, in other
- The second pillar of the MA technique is the assumption that generating a neutrally aligned knee when standing creates a biomechanically friendly knee component environment that would persist even during gait. By reducing the prosthetic joint reaction force, this would optimise the lifespan of the components. In fact, many studies have now challenged this dogma, after having found that static standing limb alignment (hip knee ankle (HKA) angle) poorly predicts the risk of long-term MATKA failure [21, 22]. This may be due to the fact the HKA angle is a dynamic (or functional) value that changes when weight bearing [23] and walking [24] and that only partly predicts the knee adduction moment [24, 25] and the medial femoro-tibial joint reaction force [26].

- The last pillar of the MA technique is the assumption that generating rectangular and identical extension and flexion gaps would be clinically beneficial. However, some recent studies suggest that preserving the physiological ligament laxity difference between the medial and lateral compartments and between the flexion and extension spaces may in fact be clinically advantageous [27].

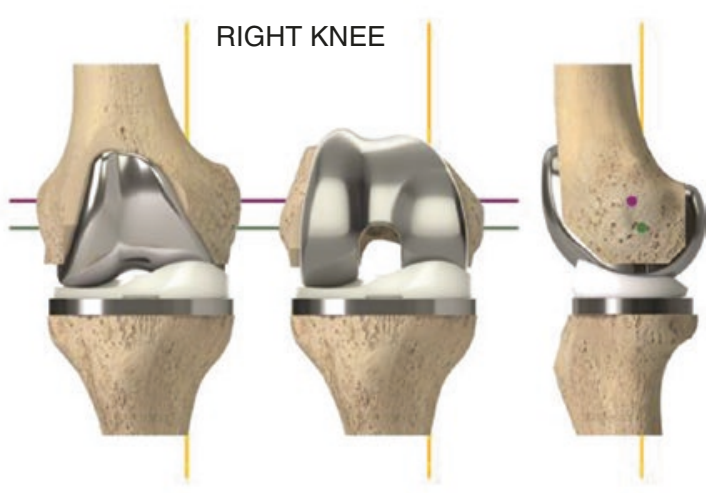

words, by performing a true total knee resurfacing. Transcondylar or cylindrical axis (green); patellar axis (purple); tibial longitudinal axis (yellow) 


\subsubsection{What Are the Intended Benefits?}

By aiming for a more physiological and more reproducible implantation, the KA technique aims to improve prosthetic knee function, patient satisfaction and component lifespan, compared to conventional techniques for knee replacement. The anatomic knee reconstruction has been shown to be clinically beneficial [28] by means of the generation of a close to physiological peri-prosthetic soft-tissue tension [29, 30] and prosthetic knee biomechanics [31-34]. Interestingly, the kinetic aspect of a KA-TKA may also be advantageous (reduced prosthetic joint reaction force) compared to MA $[31,33$, 34]. Those functional and biomechanical advantages with KA would hopefully contribute to counter the raising burden of revision in patients who are having joint replacement younger, with higher demands and expectations, and a longer life expectancy $[7,8]$.

\subsection{Planning a Kinematic Implantation}

\subsubsection{Which Patient Can Be Kinematically Implanted?}

Primary replacements requiring revision knee implants to treat a deficient knee soft-tissue envelope (e.g. MCL stretching and severe valgus knee) or severe bone loss are not eligible for KA. This is due to the design of revision implants, where the stem-implant angle dictates the implant orientation (often $6^{\circ}$ for femur and $0^{\circ}$ for tibia).

There is currently no evidence that osteoarthritic knees that require a primary replacement with sliding components lead to the preclusion of a surgeon using KA. Out of 219 consecutive unselected KA-TKAs prospectively followed for 10 years, prosthetic knees resulting in varus or valgus limb alignment $\left(>3^{\circ}\right)$ performed similarly as the ones neutrally aligned knees. Only three aseptic revisions (1.6\%) were observed and were related to technical error in component positioning [35]. Similarly, the fact that only 13 cases of patella instability were reported out of 3212 consecutive KA-TKAs indicates that the vast majority of patella-femoral joints and axial femoro-tibial rotations may be safely reproduced when kinematically implanting total knee components [36].

Nevertheless, it is likely that certain types of constitutional anatomy may be biomechanically inferior and thus clinically detrimental if reproduced (osteoarthritic knee types 2, 3 and 5; Table 16.1).

- The safe range for frontal kinematically positioned total knee components is yet to be determined [5]. This explains why some authors use KA unless the patient is an outlier, with excessive deviation from the average constitutional knee anatomy $[37,38]$. In this event, those authors would adjust the kinematic components positioning, by slightly deviating from the native anatomy, in order to fit an arbitrarily defined, range of component positioning and limb alignment $[37,38]$. This defines the concept of restricted kinematic alignment, best illustrated by the Montreal protocol (see Chap. 17) [37, 38]. The outlier constitutional knee/limb anatomies must not be confused with extra-articular deformities resulting from trauma (e.g. femoral diaphysis malunion), which are not physiological. These more often need to be corrected with an additional osteotomy at the time of TKA (one stage) or before (two stages) the TKA.

- Similarly, the safe range for axially kinematically positioned total knee components is unknown [5]. Kinematically implanting patients having an antecedent of patella instability (osteoarthritic knee type 5; Table 16.1) may seem unreasonable as reproducing a poor anatomy (e.g. excessive Q angle or trochlea groove-tibial tuberosity distance) may lead to failure. As stated above, with solely 13 cases of patella instability out of 3212 consecutive unselected KA-TKAs [36], the vast majority of patella-femoral joint anatomies and axial femoro-tibial rotations may, apparently, be safely reproduced. 
Table 16.1 Table illustrating different types of knee that make a kinematic implantation simple, complex or not indicated

\begin{tabular}{|c|c|c|c|c|c|c|}
\hline & $\begin{array}{l}\text { Simple } \\
\text { KA-TKA }\end{array}$ & \multicolumn{4}{|l|}{$\begin{array}{l}\text { Complex } \\
\text { KA-TKA }\end{array}$} & $\begin{array}{l}\text { No } \\
\text { KA-TKA }\end{array}$ \\
\hline Knee type & 1 & 2 & 3 & 4 & 5 & 6 \\
\hline Definition & $\begin{array}{l}\text { None of the } \\
\text { criteria } \\
\text { defining the } \\
\text { types } 2,3,4 \text {, } \\
5,6\end{array}$ & $\begin{array}{l}>5^{\circ} \\
\text { constitutional } \\
\text { varus }\end{array}$ & $\begin{array}{l}>5^{\circ} \\
\text { constitutional } \\
\text { valgus }\end{array}$ & $\begin{array}{l}\text { Severe bone } \\
\text { loss }\end{array}$ & $\begin{array}{l}\text { Antecedent of } \\
\text { patella } \\
\text { instability }\end{array}$ & $\begin{array}{l}\text { Deficient } \\
\text { soft-tissue } \\
\text { envelope }\end{array}$ \\
\hline $\begin{array}{l}\text { Surgical } \\
\text { planning }\end{array}$ & KA & \multicolumn{2}{|c|}{$\begin{array}{l}\text { KA or 'KA + realignment } \\
\text { osteotomy' or rKA }\end{array}$} & $\begin{array}{l}\text { KA (unless } \\
\text { revision } \\
\text { implant } \\
\text { needed) }\end{array}$ & $\begin{array}{l}\text { KA } \\
\pm \text { MPFL } \\
\text { reconstruction } \\
\pm \text { lateral } \\
\text { retinaculum } \\
\text { release and } \\
\text { VMO plasty } \\
\pm \text { extensor } \\
\text { mechanism } \\
\text { realignment }\end{array}$ & $\begin{array}{l}\text { Constrained } \\
\text { implants } \\
\text { needed, KA } \\
\text { technique } \\
\text { not indicated }\end{array}$ \\
\hline
\end{tabular}

Knee types 2, 3, 4 and 5 represent situations of complexity that are important to preoperatively recognise for refining the planning of the kinematic implantation

\subsubsection{Which Implant Design May Be Kinematically Implanted?}

It is likely that the majority of traditional primary implant designs (symmetrical sliding designs) available on the market such as medial pivot and cruciate(s) retaining or substituting designs may be suitable for a kinematic implantation. As kinematic prosthetic implantation aims to restore close to physiological knee kinematics, implant designs that promote unconstrained, physiological femoro-tibial kinematics and that preserve or replicate cruciate ligament(s) function are probably the most sensible for use. For this reason, kinematic implantations have traditionally been reported with fixed bearing cruciate-retaining implant designs [35-37, 39-42]. Nevertheless, successful kinematic implantation with mobile bearing postero-stabilised implant design has also been reported [43]. After having used cruciate-retaining and postero-stabilised designs, the author (CR) is now performing kinematic implantation with a medial pivot TKA component design [44]. By offering anteroposterior stability (substitution of both cruciate ligaments and medial meniscus) and medial implant congruency (ball in socket), medial pivot TKA design may be clinically advantageous by providing improved knee stability and reduced linear polyethylene wear. There is no study having compared the value of the multiple implant designs when kinematically positioned. Further research is therefore needed.

Asymmetric components with built-in joint line obliquity (e.g. Journey ${ }^{\mathrm{TM}}$, Genesis ${ }^{\mathrm{TM}}$ - Smith $\&$ Nephew), because of asymmetry in the thicknesses of their medial and lateral compartments, are specifically designed for mechanical implantation (thus creating the effect of an anatomical alignment - see Fig. 16.1) and are inappropriate for kinematic alignment.

\subsubsection{Which Instrumentation to use?}

Conventional gap-balancing techniques, serving to define the femoral axial rotation, are inappropriate for KA. This is because a kinematic femoral component is always implanted parallel to the posterior condylar line (neutral rotation) in order to be adequately aligned with the cylindrical (trans-condylar) axis. This is easily achieved with a posterior referencing resection guide.

KA can be performed manually $[45,46]$ or with the use of assistive technology [35, 37, 39-41, 43]. Successful implantations have been 
reported using measured-resection manual instrumentation (Chap. 24) [45, 46], navigation systems (Chap. 26) [37, 43] and personalized cutting guide (Chap. 25) [35, 39-42]. A modified gap-balancing technique for performing the tibial cut is also being assessed [47].

Technological assistance (e.g. computer, robotics or PSI) is probably most of interest with the restricted $K A$ concept $[5,37,38,48]$, by informing the surgeon about the patient's knee

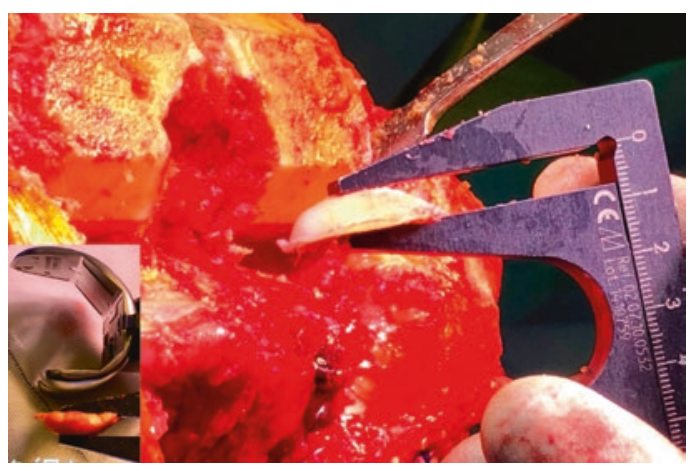

Fig. 16.3 The calliper is the key tool for successful KA implantation. Distal and posterior femoral cuts and the tibial cut must always be measured. The resection thicknesses should match those of the components, after compensating for cartilage and bone wear and the $1 \mathrm{~mm}$ kerf from the saw cut

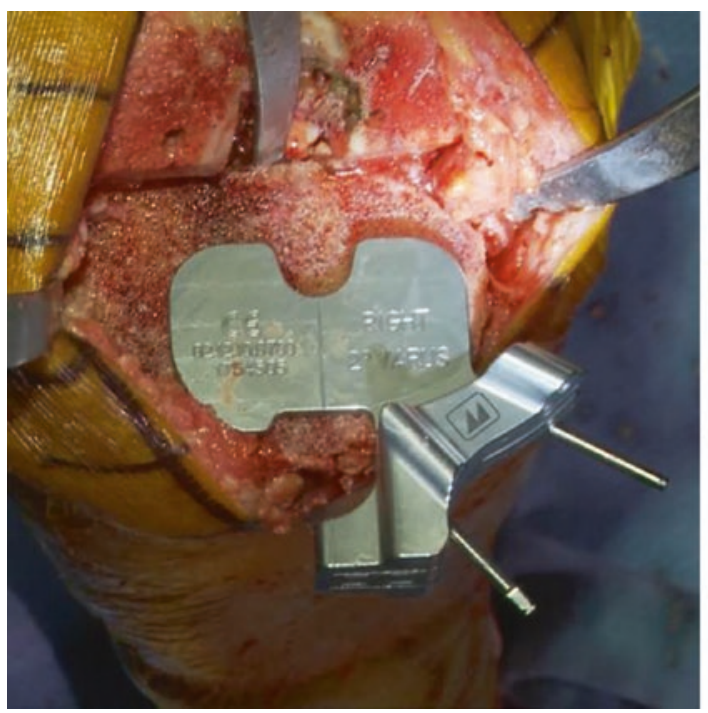

Fig. 16.4 Recently launched specific KA instrumentation $^{\mathrm{TM}}$ (Medacta, Switzerland). It helps to compensate for cartilage loss on the femoral side as well as easing the anatomy and the ability to precisely execute anatomy adjustment when needed. The restricted KA concept consists of restricting the use of the pure kinematic technique only for individual with HKA deviation above $3^{\circ}$ and/or distal femoral/ proximal tibia joint line obliquity higher than $5^{\circ}$ (Montreal protocol, see Chap. 17) [38]. Outlier patients will have their component positioning adjusted by slightly deviating from their constitutional knee anatomy (adjusted kinematic implant orientation). When performing a pure kinematic implantation (no adjustment), it remains to be seen whether technological assistance is of any clinical advantage as the kinematic components positioned with manual instrumentation have been shown to be highly reliable in terms of reproducibility of implant positioning [46, 49, 50] and clinical outcomes [45, 46]. This is the result of using reliable intra-articular anatomical landmarks to set the level and orientation of the bone cuts, knowing the expected bone resection thicknesses, controlling their quality with a calliper (measured resection technique; Fig. 16.3) and by assessing the collateral ligaments tension with spacer block and/or trial implants (ligament referencing technique) and easily refining the cuts with specific user-friendly recut guides (Fig. 16.4, and see Chap. 24).

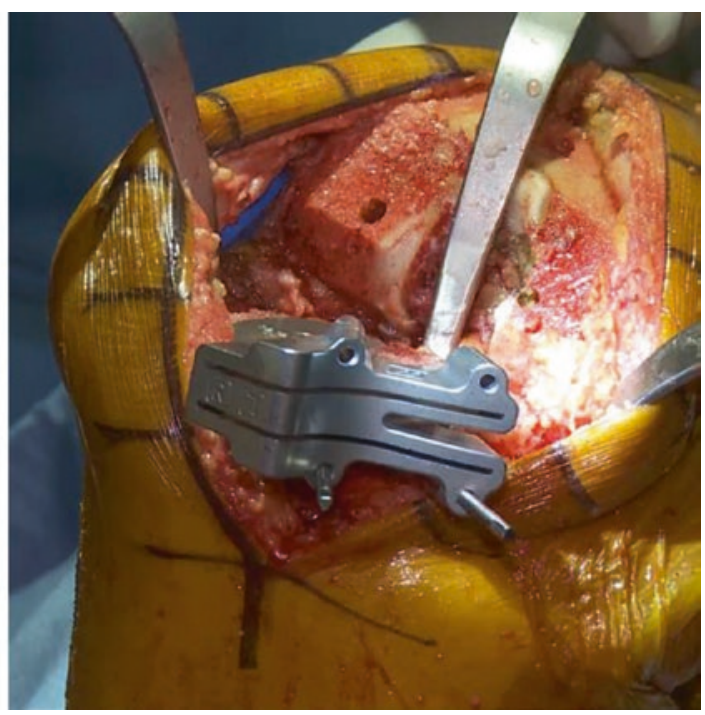

refinement of the tibial cut through the various recut guides (additional tibia varus or valgus or slope). This figure illustrates the varus/valgus recut guide 


\subsubsection{Resurface the Patella or Not?}

There is unfortunately no evidence to help with this choice. As MA and KA implantations significantly differ from each other, the evidence accumulated for the former technique can't be translated to the latter one.

MA frequently generates lateral femoral condyle prosthetic overstuffing that affects the patella balance (lateral retinaculum stretching) and biomechanics (lateral patella tilt/shift and increased lateral facet joint reaction force) when flexing the knee [11] and is sometimes responsible for MA-TKA failures [35, 36, 42]. In contrast, this significant alteration of the lateral femoral condyle anatomy does not occur when knee components are KA $[11,51,52]$ and probably explains the more physiological patella biomechanics $[33,34]$ and the rare anterior knee pain $[42,53]$ and patella instability $[35,36]$ after KA-TKA. The improved patella environment after KA-TKA, relative to MA-TKA, may have a protective effect on it, whether it has been replaced or not. This would hopefully be clinically beneficial by reducing the risk of patella-femoral joint-related complications $[35,36,42]$.

\subsubsection{Recognising a Complex Case for KA Implantation}

As KA and MA implantation significantly differ, both techniques are complex in different situations. A classification of the most frequent conditions that would make KA-TKA complex is illustrated in Table 16.1.

In contrast to MA, the frontal limb deformity is generally not a source of technical complexity with the KA technique $[11,12,29,30]$. This is because the anatomical joint reconstruction given by KA reliably restores the physiological knee soft-tissue balance whatever the constitutional limb alignment of the patient $[11,12,29,30]$. Therefore, constitutional frontal limb deformity does not add surgical complexity unless considered excessive and needing attenuation (restricted KA) or correction (additional osteotomy before or at the time of the KA-TKA). While arbitrarily defined by some authors [37, 38], the optimal deformity threshold is yet to be scientifically defined.

Complex KA-TKA is frequently found in situations of substantial articular surface bone loss. The assessment of the medial (valgus stress) and lateral (varus stress) femoro-tibial spaces before any cuts (Fig. 16.5) gives an idea of the
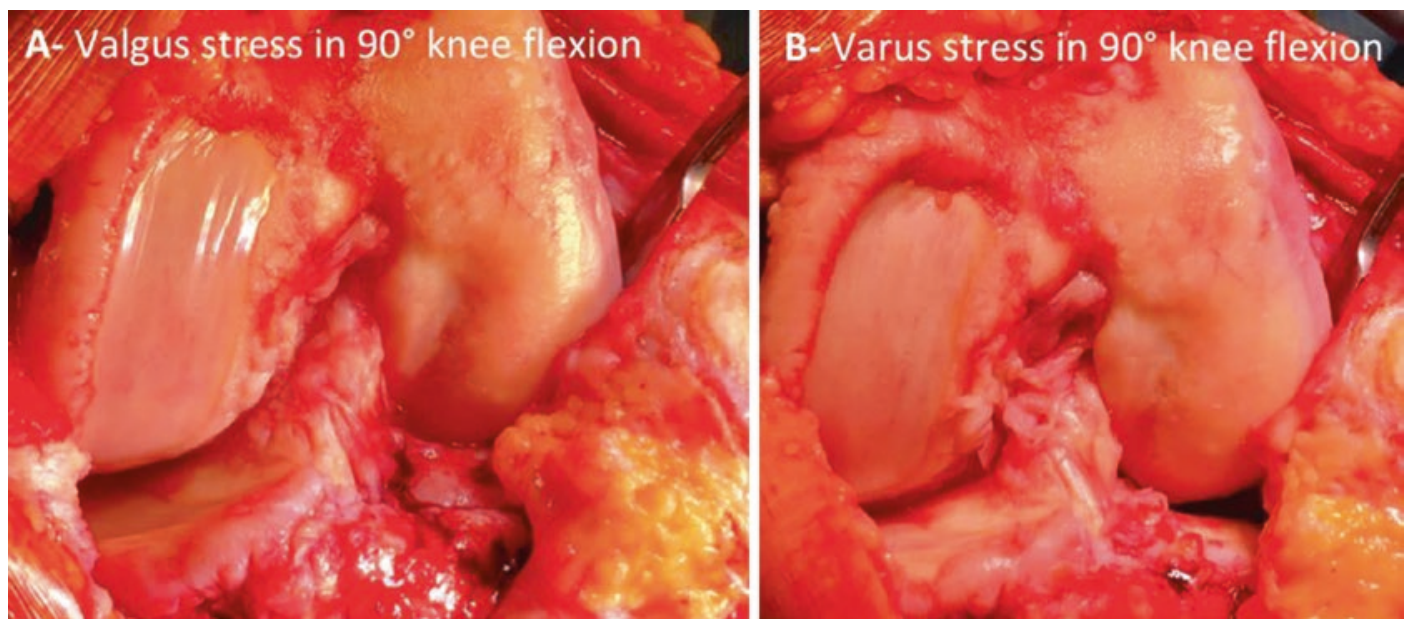

Fig. 16.5 Before performing any bone cuts, it is important to estimate the physiological knee laxity and amount of bone loss by doing varus $(\mathbf{b}, \mathbf{d})$ and valgus $(\mathbf{a}, \mathbf{c})$ stress tests in $90^{\circ}(\mathbf{a}, \mathbf{b})$ and $10^{\circ}$ knee flexion and at full extension (c, d). In this case, there is a $3 \mathrm{~mm}$ to $4 \mathrm{~mm}$ physiological lateral laxity in flexion (b) but none at full extension (d) when doing a varus stress test. In contrast, there is excessive medial laxity when doing a valgus stress test, around $5 \mathrm{~mm}$ in flexion (a) and $10 \mathrm{~mm}$ in extension (c), which suggests significant medial compartment bone loss 

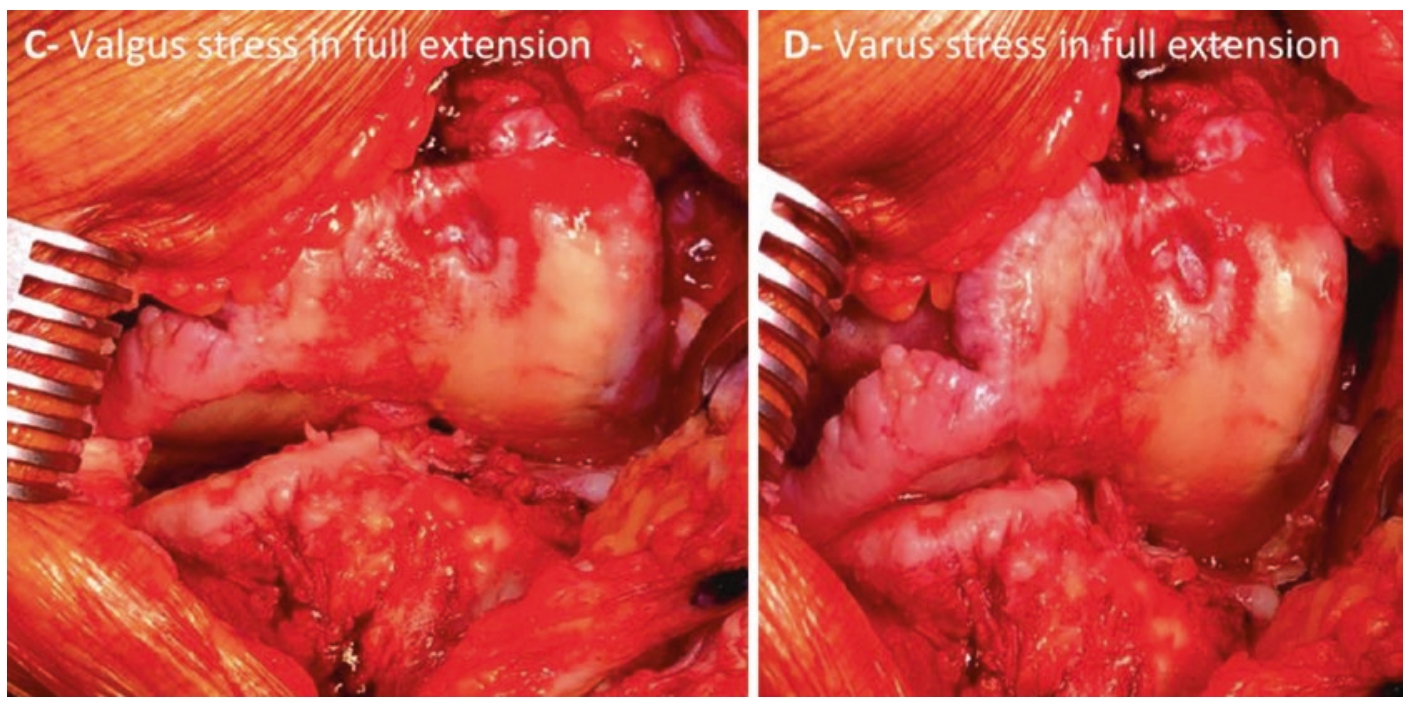

Fig. 16.5 (continued)

physiological femoro-tibial laxity and amount of bone loss and helps with planning the bone resection thickness. Then, by respecting the stepwise approach of a KA technique, with economic bone cuts followed by calliper-based quality control and potential recuts, KA in cases of substantial articular surface bone loss is usually relatively straightforward.

Patients with patella maltracking and/or a previous history of patella-femoral instability may need additional surgical correction (e.g. MPFL reconstruction, tibial tuberosity mobilisation) at the time of KA-TKA in order to optimise the patella tracking. Also, because the lateral retinaculum is often retracted in these cases, performing a lateral para-patellar arthrotomy, in addition to a plasty of the lateral retinaculum (Keblish style), may be advisable.

\subsection{Key-Points for Performing a Kinematic Implantation}

This section will only highlight key points of the KA technique. More details are provided in Chap. 24. The KA surgical technique significantly differs from the conventional MA tech- nique. The only similarity between the techniques is in the execution and goal for sagittal femoral component positioning (Table 16.2) [5, 54]. The knee bony landmarks traditionally used for MA implantation are of little use when positioning implants using the KA technique $[55,56]$. This is because the KA technique pays attention to intraarticular anatomical reference landmarks and strives to recreate the constitutional knee joint line orientation and knee laxity. In contrast, the MA technique focuses primarily of extra-articular long-bone mechanical axes and aims for mechanical component positioning [5, 54].

The KA technique follows a step-wise execution with the main steps being listed in Fig. 16.6. The KA implantation is traditionally a measured resection, femur first technique [45]. There are a few helpful tricks:

- First, always estimate the individual physiological knee laxity and amount of bone loss before performing any bone cuts, by varus/ valgus stressing the knee throughout the knee range of motion (Fig. 16.5).

- Second, always check the quality of the bone resection with a calliper (Fig. 16.3). The expected thickness of the bone cut is easily 
Table 16.2 Kinematic alignment (KA) and mechanical (MA) alignment are two different techniques for implanting knee components that only have in common the sagittal positioning of the femoral component

\begin{tabular}{|c|c|c|c|}
\hline & & KA technique & MA technique \\
\hline \multirow{4}{*}{$\begin{array}{l}\text { Femoral } \\
\text { component } \\
\text { positioning }\end{array}$} & Flexion & $\begin{array}{l}\text { Follows distal femoral } \\
\text { bowing }\end{array}$ & Follows distal femoral bowing \\
\hline & Varus-valgus & $\begin{array}{l}\text { Parallel to the distal femoral } \\
\text { joint line (considering } \\
\text { articular surface wear) }\end{array}$ & $\begin{array}{l}\text { Systematic and perpendicular to the femoral } \\
\text { mechanical axis }\end{array}$ \\
\hline & Rotation & $\begin{array}{l}\text { Parallel to the posterior } \\
\text { condylar line } \\
\text { Always measured resection } \\
\text { and posterior referencing } \\
\text { techniques for a compromise } \\
\text { done only on the trochlear } \\
\text { offset }\end{array}$ & $\begin{array}{l}\text { External rotation relative to the posterior } \\
\text { condylar line. Measured resection or gap- } \\
\text { balancing techniques. Posterior or anterior } \\
\text { referencing techniques for a compromise done } \\
\text { either on the flexion gap or on the trochlear offset, } \\
\text { respectively }\end{array}$ \\
\hline & $\begin{array}{l}\text { Medio- } \\
\text { lateral }\end{array}$ & Centred on the notch & Slightly lateralised \\
\hline \multirow[t]{3}{*}{$\begin{array}{l}\text { Tibial } \\
\text { component } \\
\text { positioning }\end{array}$} & Varus-valgus & $\begin{array}{l}\text { Parallel to the proximal tibial } \\
\text { joint line (considering the } \\
\text { wear) }\end{array}$ & $\begin{array}{l}\text { Systematic and perpendicular to the tibial } \\
\text { mechanical axis }\end{array}$ \\
\hline & Slope & $\begin{array}{l}\text { Parallel to the medial plateau } \\
\text { slope }\end{array}$ & $\begin{array}{l}\text { Systematic and varies between } 2^{\circ} \text { and } 7^{\circ} \text { relative } \\
\text { to the sagittal tibia mechanical axis }\end{array}$ \\
\hline & Rotation & $\begin{array}{l}\text { Parallel to lateral plateau } \\
\text { long-axis }\end{array}$ & $\begin{array}{l}\text { Towards the medial third of the anterior tibial } \\
\text { tuberosity }\end{array}$ \\
\hline \multirow[t]{2}{*}{$\begin{array}{l}\text { Soft-tissue } \\
\text { release }\end{array}$} & $\begin{array}{l}\text { Femoro- } \\
\text { tibial joint }\end{array}$ & $\begin{array}{l}\text { None-close or physiological } \\
\text { knee laxity automatically } \\
\text { restored after bone cuts }\end{array}$ & $\begin{array}{l}\text { Frequent for creating identical rectangular } \\
\text { flexion and extension gaps }\end{array}$ \\
\hline & $\begin{array}{l}\text { Lateral } \\
\text { retinaculum }\end{array}$ & $\begin{array}{l}\text { Rarely —only in case of } \\
\text { preoperative abnormal patella } \\
\text { tracking with retracted lateral } \\
\text { retinaculum ligament }\end{array}$ & $\begin{array}{l}\text { Often performed to palliate the frequent } \\
\text { prosthetic overstuffing of the lateral femoral } \\
\text { condyle }\end{array}$ \\
\hline
\end{tabular}

calculated by deducting $1 \mathrm{~mm}$ from the implant thickness for the saw blade (kerf) thickness and by estimating the amount of articular surface wear. The cartilage thickness is frequently approximately $2 \mathrm{~mm}$ on the distal and posterior parts of the femoral condyles [57].

- Last, unless using technological assistance, perform an economical tibial cut on the worn side (Fig. 16.7) as the amount of bone loss is difficult to estimate precisely and it is easy to secondarily refine the tibia cut by using userfriendly KA-dedicated recut guides (Figs. 16.4 and 16.7).

If you face a femoro-tibial soft-tissue imbalance (tightness and/or excessive laxity) and the integrity of the knee soft-tissue envelope is still respected (no MCL or popliteal section), this is often because the tibial cut is improper. This is because performing a kinematic femoral component implantation is relatively straightforward and highly reproducible [49]. The solution is therefore to perform bone recuts by using specific recut guides that easily enable additional degrees of varus/valgus/slope to be made or an additional two millimetres of tibia to be cut. In summary, the kinematic tibial implant positioning is made reproducible by a combination of measured resection and ligament referencing techniques. The decision tree for solving imbalance while performing a kinematic implantation is illustrated in Fig. 16.8. 
Fig. 16.6 The

kinematic alignment technique for implanting total knee components follows a step-wise process that helps at making the implantation reliable

\section{SURGICAL TECHNIQUE}

\section{KA - TKA}
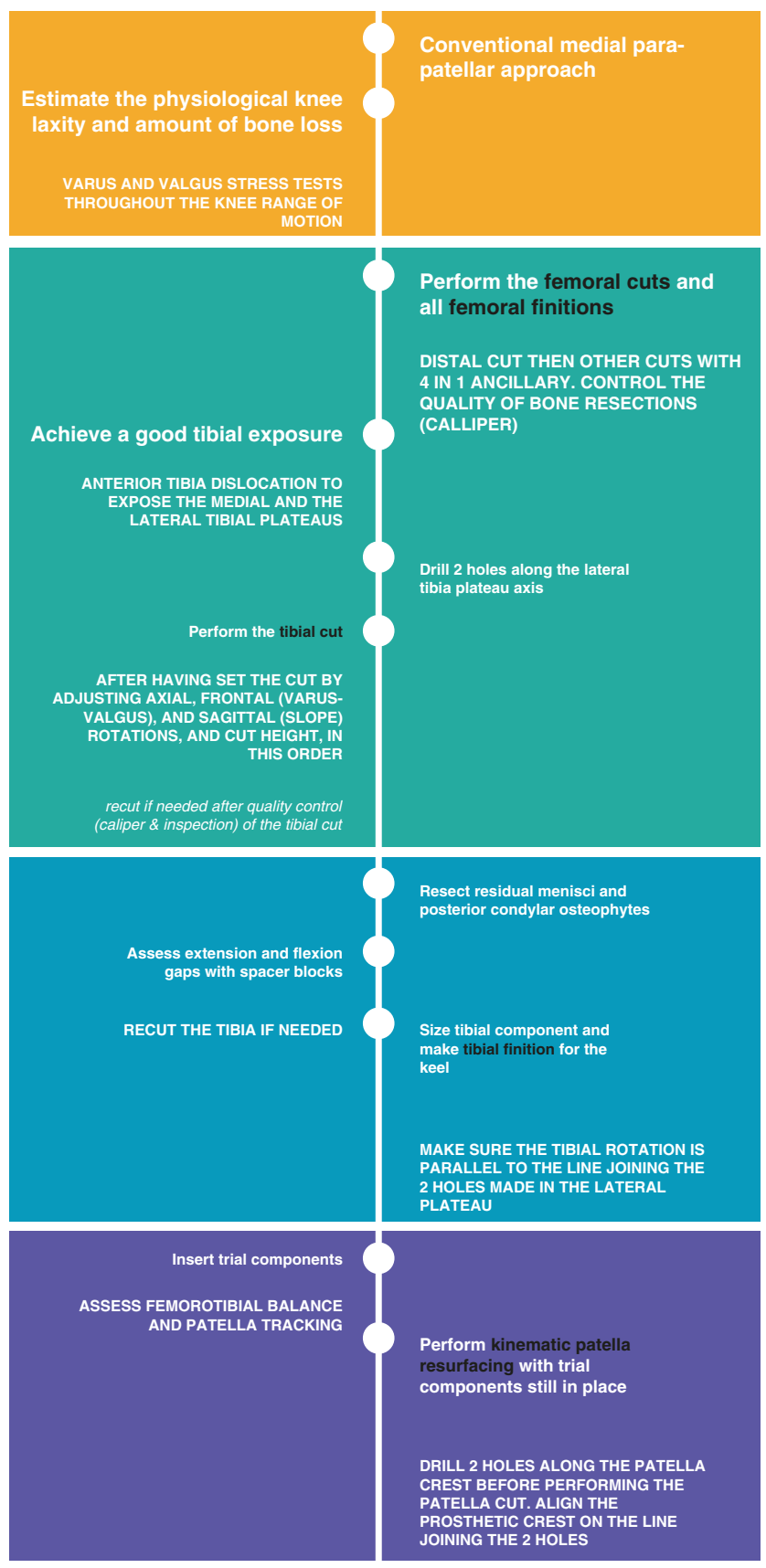

Final components implantation \& closure 

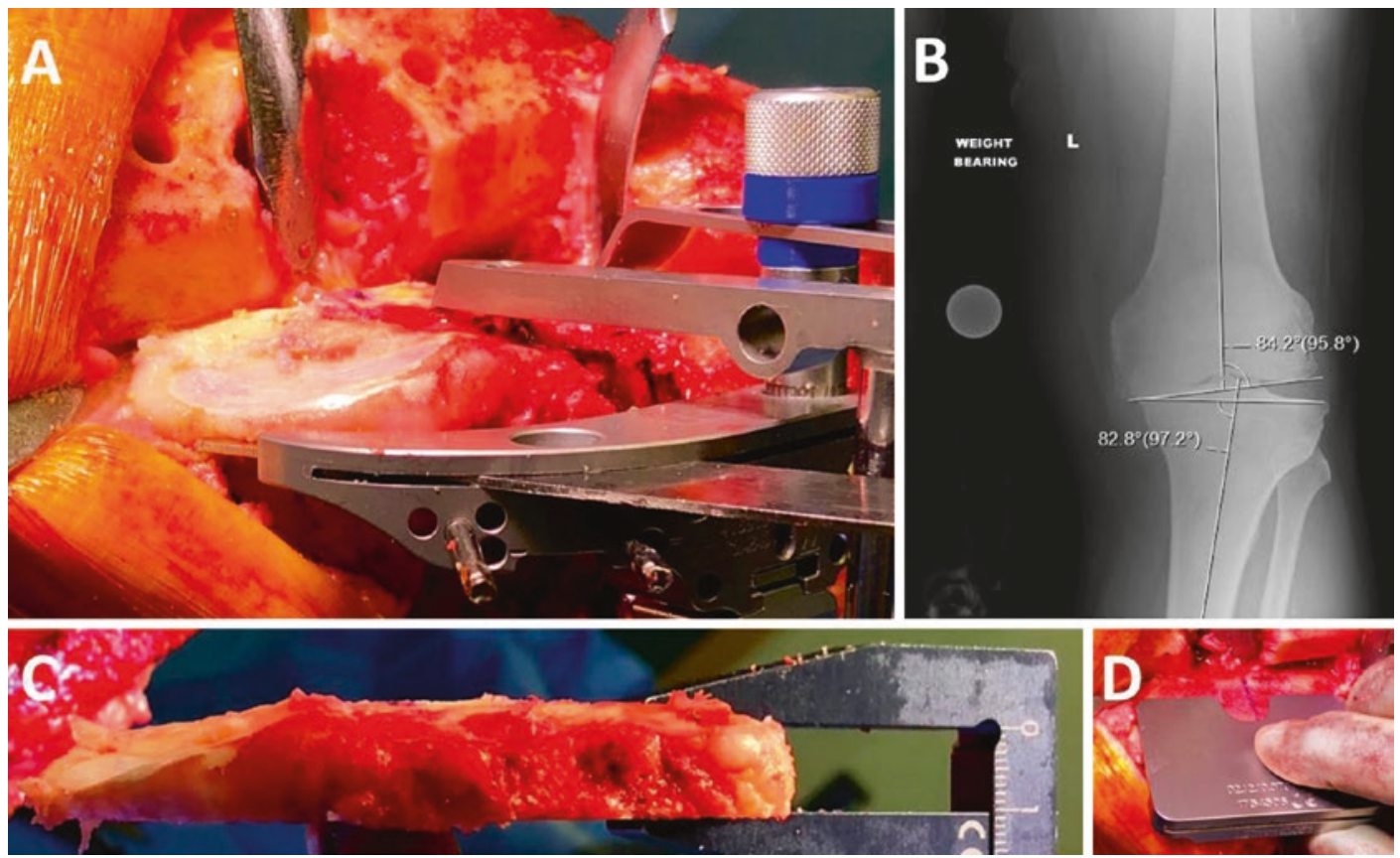

Fig. 16.7 Performing a conservative tibial bone resection on the worn medial side $(\mathbf{a}, \mathbf{c})$ is recommended as it is not easy to precisely estimate the amount of bone loss $(\mathbf{a}, \mathbf{b})$. If the knee feels tight when assessing the flexion and extension gaps (spacer block), refinement of the tibial cut will be easily executed with the use of specific recut guides (d)

\begin{tabular}{|c|c|c|c|c|c|}
\hline \multicolumn{6}{|c|}{$\begin{array}{l}\text { DECISION-TREE FOR BALANCING A CALIPERED KINEMATICALLY ALIGNED } \\
\text { MEDACTA GMK SPHERE CS TKA }\end{array}$} \\
\hline $\begin{array}{l}\text { Tight in Flexion } \\
\text { \& Extension }\end{array}$ & $\begin{array}{l}\text { Tight in Flexion } \\
\text { Well-Balanced in } \\
\text { Extension }\end{array}$ & $\begin{array}{l}\text { Tight in Extension } \\
\text { Well-Balanced in } \\
\text { Flexion }\end{array}$ & $\begin{array}{l}\text { Well-Balanced } \\
\text { in Extension and } \\
\text { Loose in Flexion }\end{array}$ & $\begin{array}{l}\text { Tight Medial \& } \\
\text { Loose Lateral in } \\
\text { Extension }\end{array}$ & $\begin{array}{l}\text { Tight Lateral and } \\
\text { Loose Medial in } \\
\text { Extension }\end{array}$ \\
\hline $\begin{array}{l}\text { Recut tibia and } \\
\text { remove } 1-2 \mathrm{~mm} \\
\text { more bone. }\end{array}$ & $\begin{array}{l}\text { Confirm complete } \\
\text { resection of the } \\
\text { PCL. } \\
\text { Increase posterior } \\
\text { slope until natural } \\
\text { A-P offset is } \\
\text { restored at } 90^{\circ} \\
\text { of flexion. }\end{array}$ & $\begin{array}{l}\text { Remove posterior } \\
\text { osteophytes. } \\
\text { Strip posterior } \\
\text { capsule. } \\
\text { Insert trial } \\
\text { components \& } \\
\text { gently manipulate } \\
\text { knee into extension. }\end{array}$ & $\begin{array}{l}\text { Add thicker insert } \\
\text { and recheck knee } \\
\text { extends fully. } \\
\text { If still loose in } \\
\text { flexion, then reduce } \\
\text { slope or resect } \\
1-2 \text { mm bone } \\
\text { from distal femur } \\
\text { and add thicker } \\
\text { GMK Sphere CS } \\
\text { insert. }\end{array}$ & $\begin{array}{l}\text { Remove medial } \\
\text { osteophytes. } \\
\text { Reassess. } \\
\begin{array}{c}\text { Recut tibia in } 1-2^{\circ} \\
\text { more varus. }\end{array} \\
\text { Insert } 1 \mathrm{~mm} \text { thicker } \\
\text { insert. }\end{array}$ & $\begin{array}{l}\text { Remove lateral } \\
\text { osteophytes. } \\
\text { Reassess. } \\
\begin{array}{c}\text { Recut tibia in } 1-2^{\circ} \\
\text { more valgus. }\end{array} \\
\text { Insert } 1 \mathrm{~mm} \text { thicker } \\
\text { insert. }\end{array}$ \\
\hline
\end{tabular}

Fig. 16.8 Decision tree for balancing a kinematically aligned TKA 


\subsection{Current Evidence}

The KA technique has been developed for trying to reduce the high proportions of dissatisfaction [6] and residual complications $[7,8,10]$ that traditionally affect MA-TKA and are probably as a result of non-physiological (neglecting of unique individual knee anatomy and laxity) $[5,11,14$, $31,33,34]$ and unreliable (high rate of uncorrectable collateral ligament imbalance) [11, 12] implantation. Studies having assessed the value of KA-TKA have flourished over the last years, and the promises seem to have been met.

The KA technique generates high prosthetic knee function and a more natural feeling. Seven studies have compared KA and MA patients at short term (1-2 years), including five randomised controlled trials $[39-42,58]$ and two matched casecontrol study [32, 43]. All have reported better functional scores for KA patients, while this was statistically significant for only five studies [32, 41-43, 58]. In addition, a national multicentre survey in the USA found KA patients to be three times more likely to report their knee to feel "normal" [6]. Faster recovery for KA patients [40, 59], reduced risk of anterior knee pain $[42,53]$ and similar failure rates [39-43, 53, 58] were other interesting findings from those comparative studies. Three meta-analyses $[28,60,61]$ concluded the superiority of the KA technique in terms of prosthetic function and recovery time, with a similar low failure rate. High functional scores have been shown to persist 10 years after implantation, with no difference between different groups of limb alignment (varus $>3^{\circ}$, neutral, valgus $>3^{\circ}$ ) [35]. The faster recovery of KA patients could be the consequence of a more physiological and soft-tissue-friendly prosthetic knee implantation. This superiority is even more emphasised when the excellent clinical outcomes for KA patients were achieved despite the use of recently recalled Otismed ${ }^{\mathrm{TM}}$ cutting guides $[39-42,53]$ and by surgeons likely in their learning curve for the KA technique. In contrast, MA implantations, which were often found to be inferior to KA implantation, were performed by surgeons familiar with the technique and sometimes using navigation assistance $[39,43,58]$.

With short-term data, KA prostheses rarely failed. The early complication rates (initial 1-2 years after implantation) were reported to be similar between KA and MA patients [39-43, 53, 58]. The 10-year aseptic revision rate has been reported at $1.6 \%$ with 1 tibial component loosening and 2 patella recurrent instabilities out of 219 consecutive unselected KA-TKAs [35]. There were no differences between varus, neutral and valgus groups of limb alignment [35]. Also, only 13 cases of patella instability were reported out of 3212 consecutive kinematically implanted prosthetic knee patients during a 9-year period [36]. KA implantation, therefore, results in high implant survival at 10 years regardless of the level of preoperative deformity and whether the postoperative alignment of the tibial component, knee and limb are varus and valgus outlier ranges according to MA criteria.

The KA technique is reliable as it accurately kinematically positions the knee components $[46,49,50]$. Studies have demonstrated that KA components with manual instrumentation is highly reproducible for both femoral $[46,49]$ and tibial $[46,50]$ components. Also, the KA technique has been shown to properly restore physiological knee laxity [29, 30].

The KA technique is more physiological as it is generating close to native biomechanics. Many studies have shown that the femoro-tibial $[31,32$, 62] and patellofemoral [33, 34] KA prosthetic kinematics and kinetics (or biomechanics) more closely resemble those of the native knee, when compared to mechanically aligned TKA. Interestingly, it seems that kinematic implantation may also be kinetically more advantageous than mechanical implantation by better aligning the knee joint line parallel to the ground in situations of weight bearing [48, 63], leading to reduced deleterious shear stress on the bearing surfaces and component fixation interface. KA alignment also reduces the joint reaction forces at the lateral patella-femoral facet $[33,34]$ and through the medial femoro-tibial compartment [31]. The improved patellofemoral kinetics [33, 34] may be explained by the prosthetic trochlea anatomy in the kinematically positioned femoral component being closer to the native trochlea groove alignment $[52,64]$. The improved tibiofemoral kinetics [31] may be explained by the more physiological gait pattern after KA implantation that results in a lower knee adduction lever arm and, subsequently, a reduced knee adduction 
moment, despite the fact that lower limbs were slightly more varus [31]. This is not surprising when one realises that the frontal limb alignment (HKA angle) is a dynamic value $[23,24]$ that has been shown to poorly predict the knee adduction moment [24, 25] and the medial femoro-tibial joint reaction force [26]. The likely biomechanical advantage conferred to KA prosthesis may explain the very low rate of component failure that has been observed after KA [35].

\subsection{Specific Component Designs for Kinematic Implantation?}

Kinematically positioning contemporary knee components enables the restoration of the femoro-tibial joint line 3D orientation [46, 49], but it fails to accurately reproduce the individual trochlea anatomy [51, 52, 64]. This poor trochlea reconstruction is related to the fact that kinematic positioning of monoblock femoral components focuses on the reconstruction of the femoro-tibial joint line, with no possibility to fine-tune the prosthetic groove orientation. While this poor prosthetic trochlea anatomical reconstruction has not been responsible for catastrophic failure [5, $35,36]$, it may nonetheless hinder optimal clinical outcomes of KA prosthetic knee. Some trochlea anatomy variations may therefore benefit from a more personalized reconstruction.

The native trochlea anatomy has been shown to be highly variable between people $[3,52]$ and poorly predicted by the frontal limb/knee anatomical parameters [65]. Therefore, potential solutions to a more personalized trochlea reconstruction are threefold:

1. New modular femoral component designs offer the possibility to intraoperatively finetune the groove orientation/radius and trochlea stuffing (Fig. 16.9).
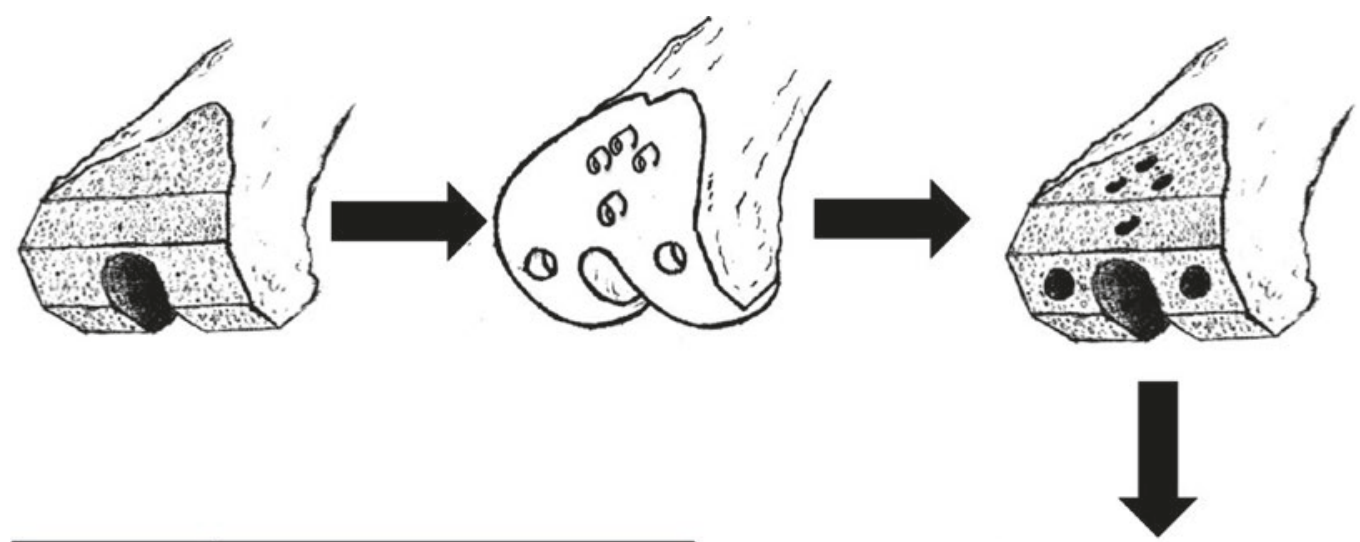

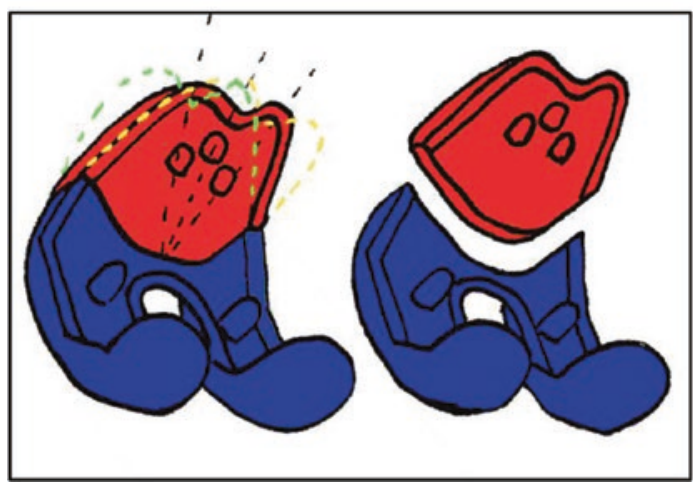

Fig. 16.9 A modular total femoral component may be one solution for restoring the individual femoro-tibial and patellofemoral joints anatomy and hopefully make clinical outcomes of KA patients even better. The surgeon would be offered the intraoperative ability to fine-tune the

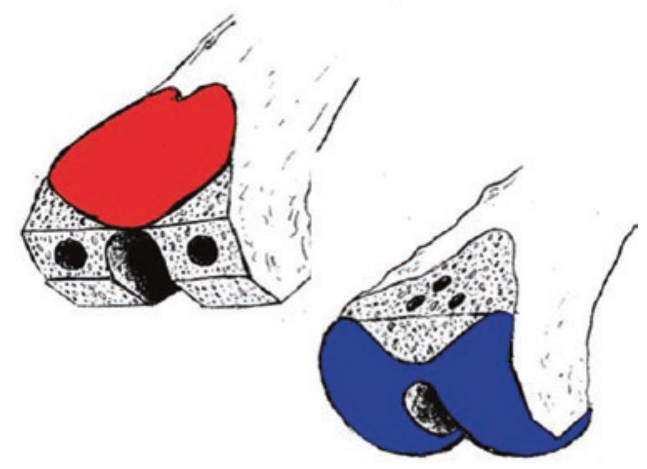

trochlea reconstruction (stuffing and groove orientation) and/or patella tracking by selecting through a wide range of modular trochlea designs that differ by their stuffing and groove orientation 
2. Already existing custom femoral component (Origin $^{\mathrm{TM}}$-Symbios, Yverdon-les-Bains, Switzerland-Fig. 16.10, Chap. 22).

3. New monoblock femoral component designs displaying various trochlea anatomies. The cost-effectiveness of the last two options may be questioned considering the current economic trend.

\subsection{Conclusion}

KA-TKA is a surgical technique that may help better reproduce physiological knee function without the need for soft-tissue release. The vast majority of osteoarthritic patients are eligible for a KA-TKA. Because the surgical technique is not demanding and complex cases are rare,
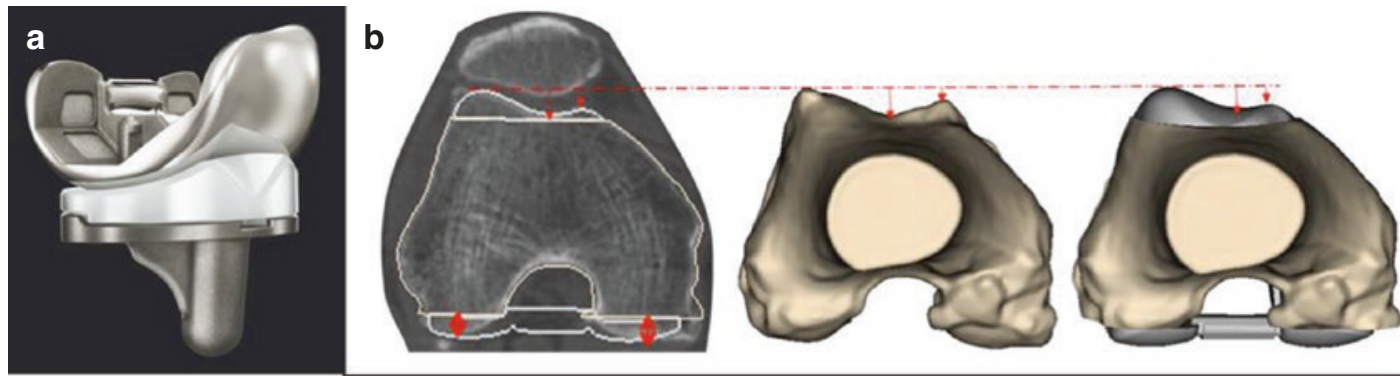

J-Curve : Lateral Condyle

J-Curve : Trochlea

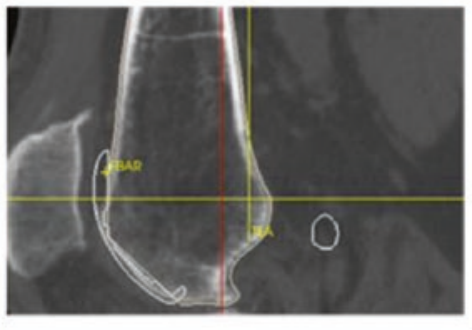

J-Curve : Medical Condyle

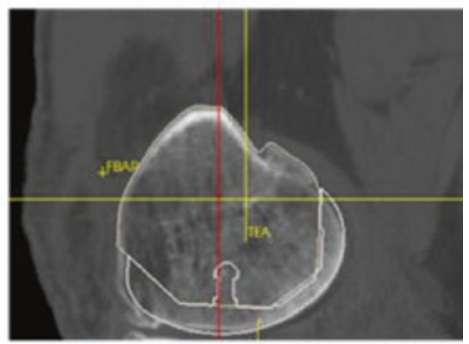

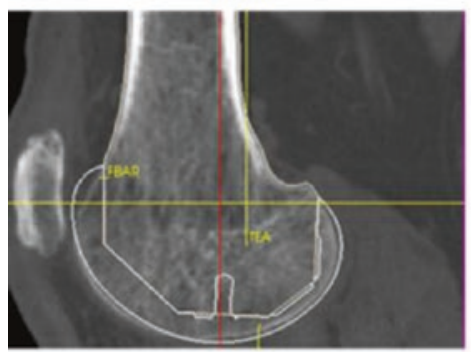

M-L Trochlea
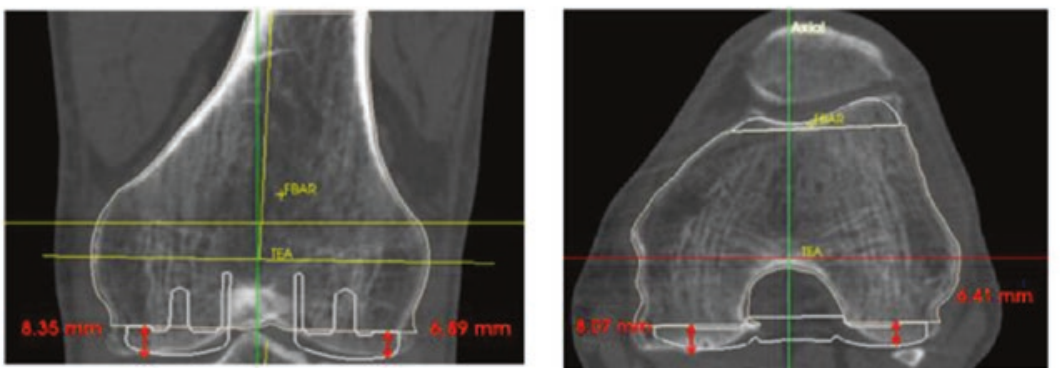

Fig. 16.10 The custom Origin ${ }^{\mathrm{TM}}$ total femoral component (Symbios, Yverdon-les-Bains, Switzerland) may be one solution for restoring the individual femoro-tibial and patellofemoral joints anatomy and hopefully make clinical

outcomes of KA patients even better. The Origin ${ }^{\mathrm{TM}}$ (a) enables restoration of the individual trochlea (b) and femoro-tibial (c) anatomy 
KA is reliable for most patients. KA implantation results in favourable implant survival and function at 10 years in a wide range of preoperative anatomies. Because the whole knee biomechanic environment is improved, it is hoped that component lifespan will also be improved. In the event of severe constitutional limb deformity, the kinematic component positioning may need to be adjusted in order to better suit the actual prosthetic fixation and bearing limitations; this defines the restricted KA concept. Long-term outcomes of KA patients still need to be defined. New TKA component designs that better match patients' knee anatomy and help replicate native knee kinematics may need consideration.

\subsection{Case Illustration}

A 66-year-old patient presented with painful, bilateral, severely degenerated knees. In the left knee, the patient had a correctable $10^{\circ}$ to $15^{\circ}$ varus deformity and a varus trust when walking. The knee range of motion was normal.
On plain radiographs (Fig. 16.11), there was bilateral, medial femoro-tibial bone-on-bone osteoarthritis. The left knee had a severe varus deformity with frontal femoro-tibial subluxation and some medial bone loss making the kinematic implantation slightly more complex than usual (knee type 5-Table 16.1).

Before performing any bone cuts on the left knee, the medial and lateral femoro-tibial laxities were assessed (Fig. 16.5), and an abnormal severe medial laxity was observed in full extension (Fig. 16.5b).

As shown in Fig. 16.12, the remaining cartilage thicknesses were assessed with a scalpel on the distal (Fig. 16.12a, b) and posterior (Fig. 16.12c, d) parts of each femoral condyle and on the lateral tibial plateau (Fig. 16.12e). There was no cartilage left on the distal medial condyle (Fig. 16.12a) and medial plateau and approximately $1 \mathrm{~mm}$ of cartilage loss on the posterior part of the medial condyle (Fig. 16.12c). $2 \mathrm{~mm}$ and $1 \mathrm{~mm}$ were then compensated for medially when performing the distal and posterior femoral cuts, respectively. Distal and posterior cuts were measured with a calliper and were within $0.5 \mathrm{~mm}$ of the plan.
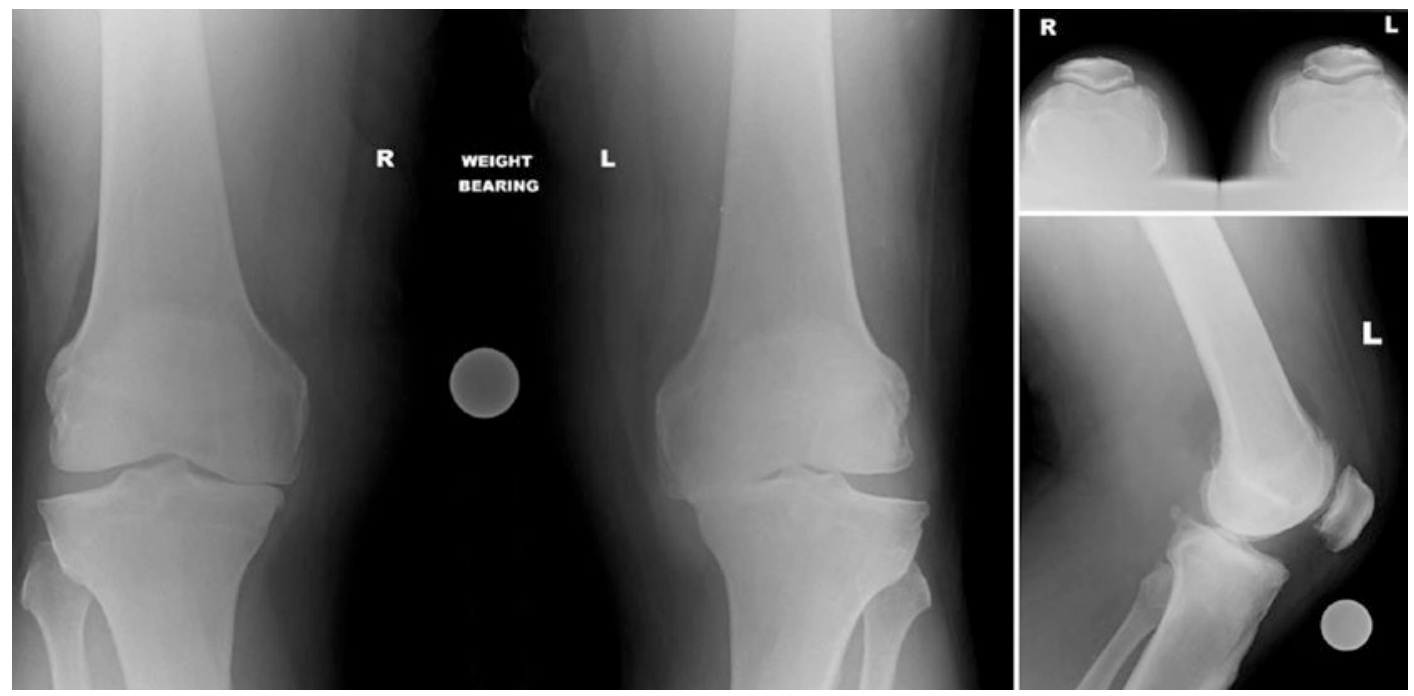

Fig. 16.11 Pre-operative knee radiographs 

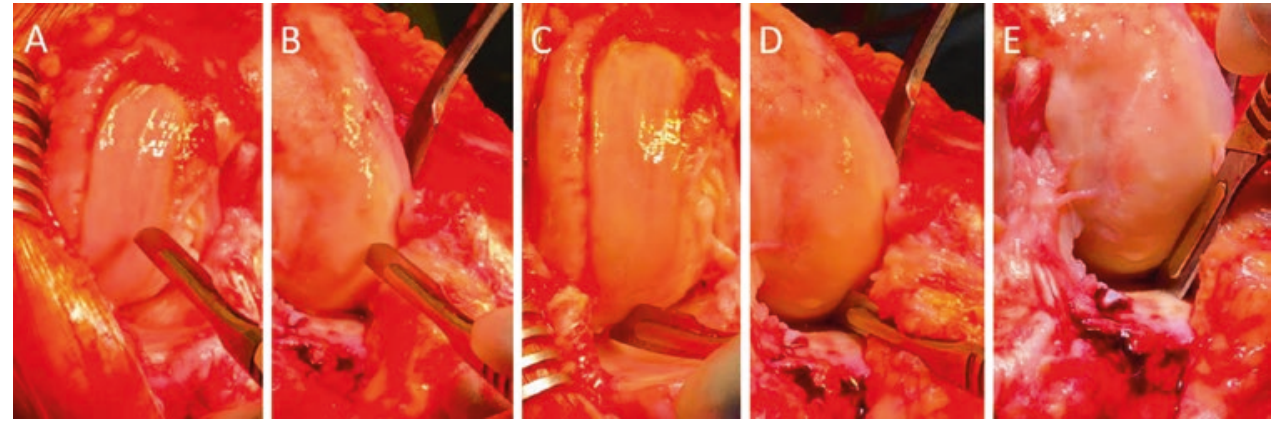

Fig. 16.12 Intra-operative estimation of cartilage thickness on the distal (a) and posterior (c) parts of the medial femoral condyle, the distal (b) and posterior (d) parts of the lateral femoral condyle, and the lateral tibia plateau (e)
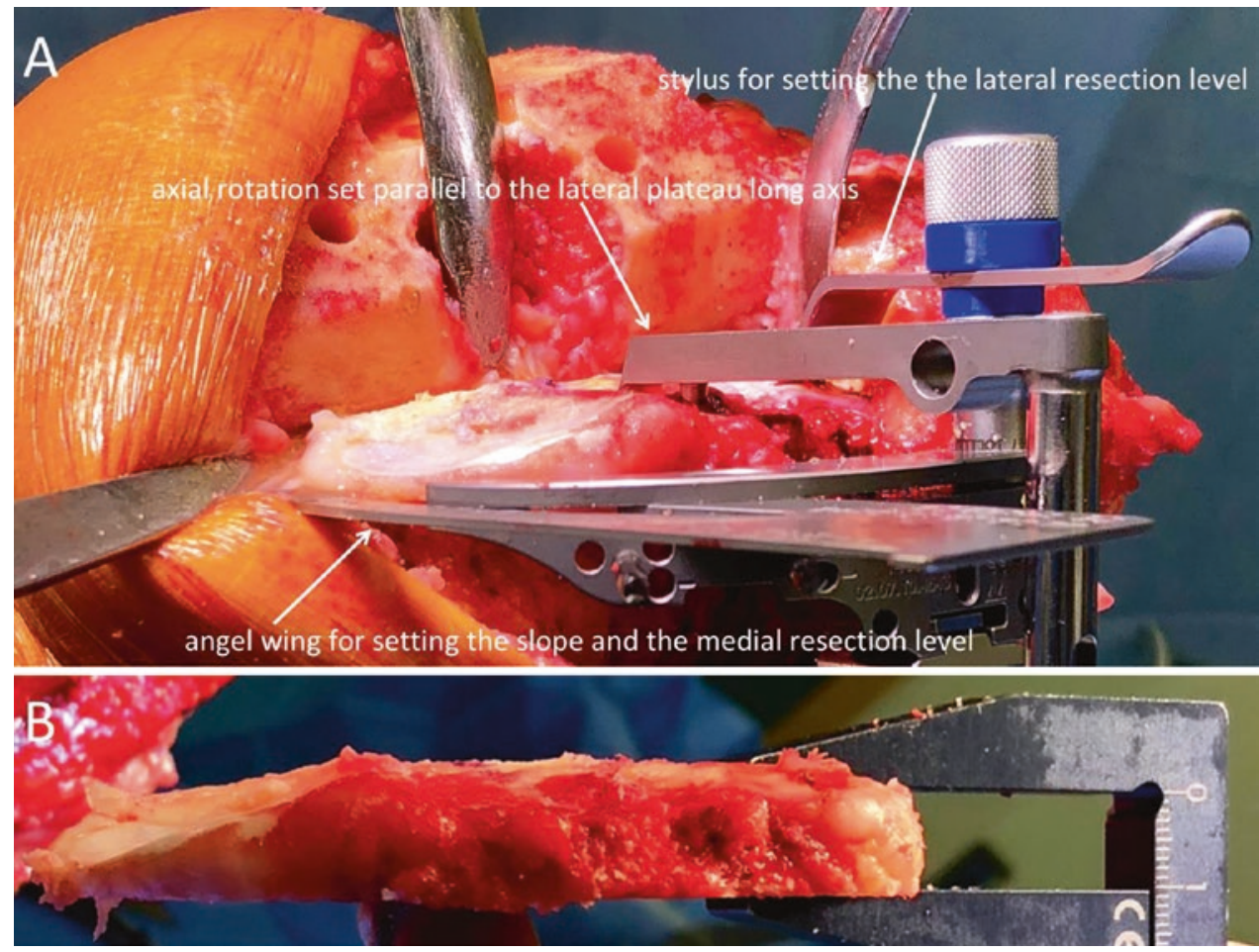

Fig. 16.13 Intra-operative photos illustrating the instrumentation setting to perform a kinematic tibial cut (a) and the quality assessment of the tibial cut with use of a caliper (b)

The extra-medullary alignment guide was used to stabilise the tibial cutting guide (Fig. 16.13a) while setting its orientation with the use of an angel wing and stylus. The tibial cut was done economically medially as the exact amount of medial plateau bone loss was unknown. The tibial cut was measured, revealing $10 \mathrm{~mm}$ was cut laterally and $3 \mathrm{~mm}$ medially (Fig. 16.13b).
The flexion and extension gaps were assessed with the use of spacer block (Fig. 16.14). The $90^{\circ}$ flexion gap was found tighter, notably medially (Fig. 16.14a), than the gap at $10^{\circ}$ of knee flexion (Fig. 16.14c). A recut of the tibia for an additional $2^{\circ}$ of slope was performed.

After cementation of the final components (Fig. 16.15), patella tracking was judged 

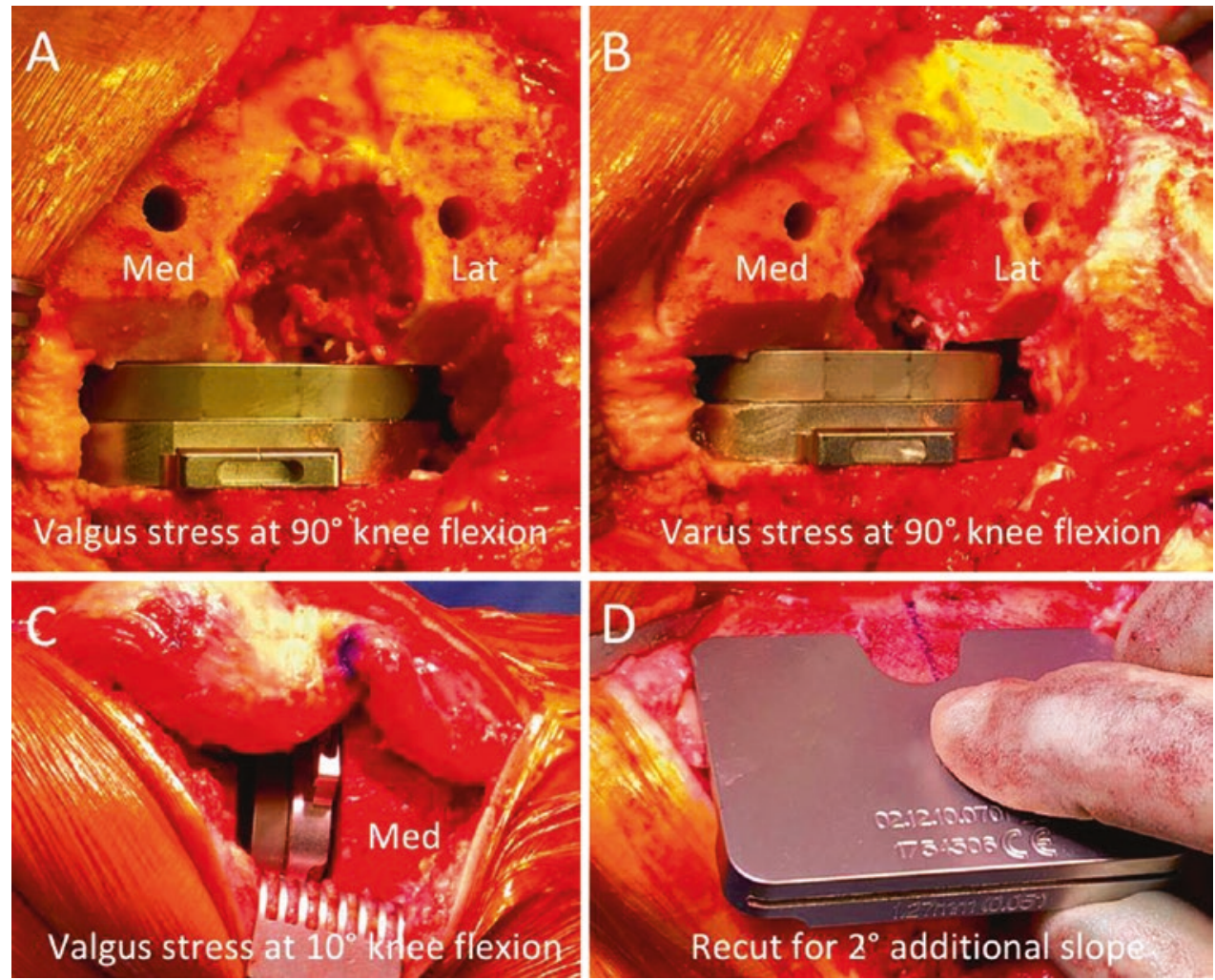

Fig. 16.14 Intra-operative photos illustrating the assessment of the residual femoro-tibial laxity with use of spacer block: medial (a) and lateral (b) knee compartment laxity in 90 degrees flexion, medial knee compartment laxity in 10 degrees flexion (c). As the adequacy of

the femoral kinematic cuts was easily confirmed by quality check (calliper) and the femoro-tibial flexion gap was found excessively tight both medially and laterally, it was decided to recut the tibia inorder to slightly increase the slope $(\mathbf{d})$
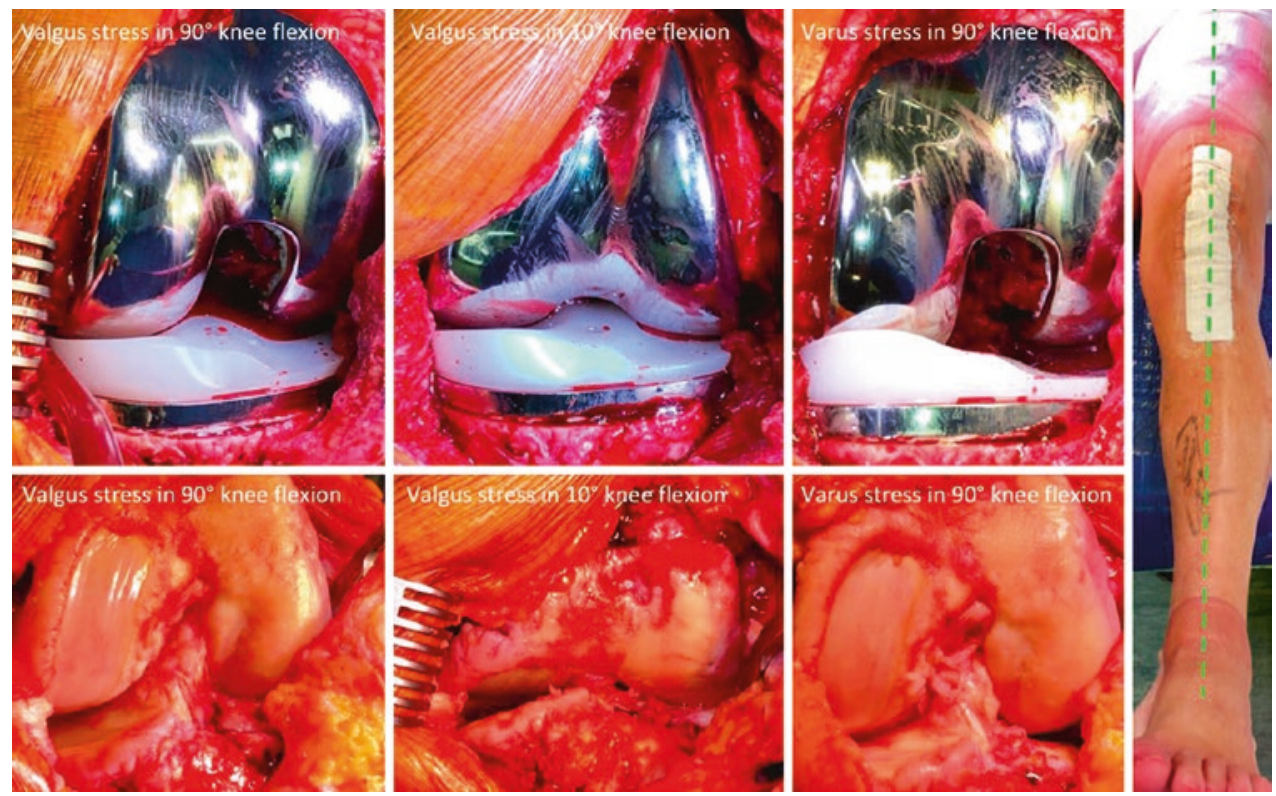

Fig. 16.15 Intra- and post-operative photos illustrating the pre- and post-implantation femoro-tibial laxities and the prosthetic lower limb alignment, respectively 

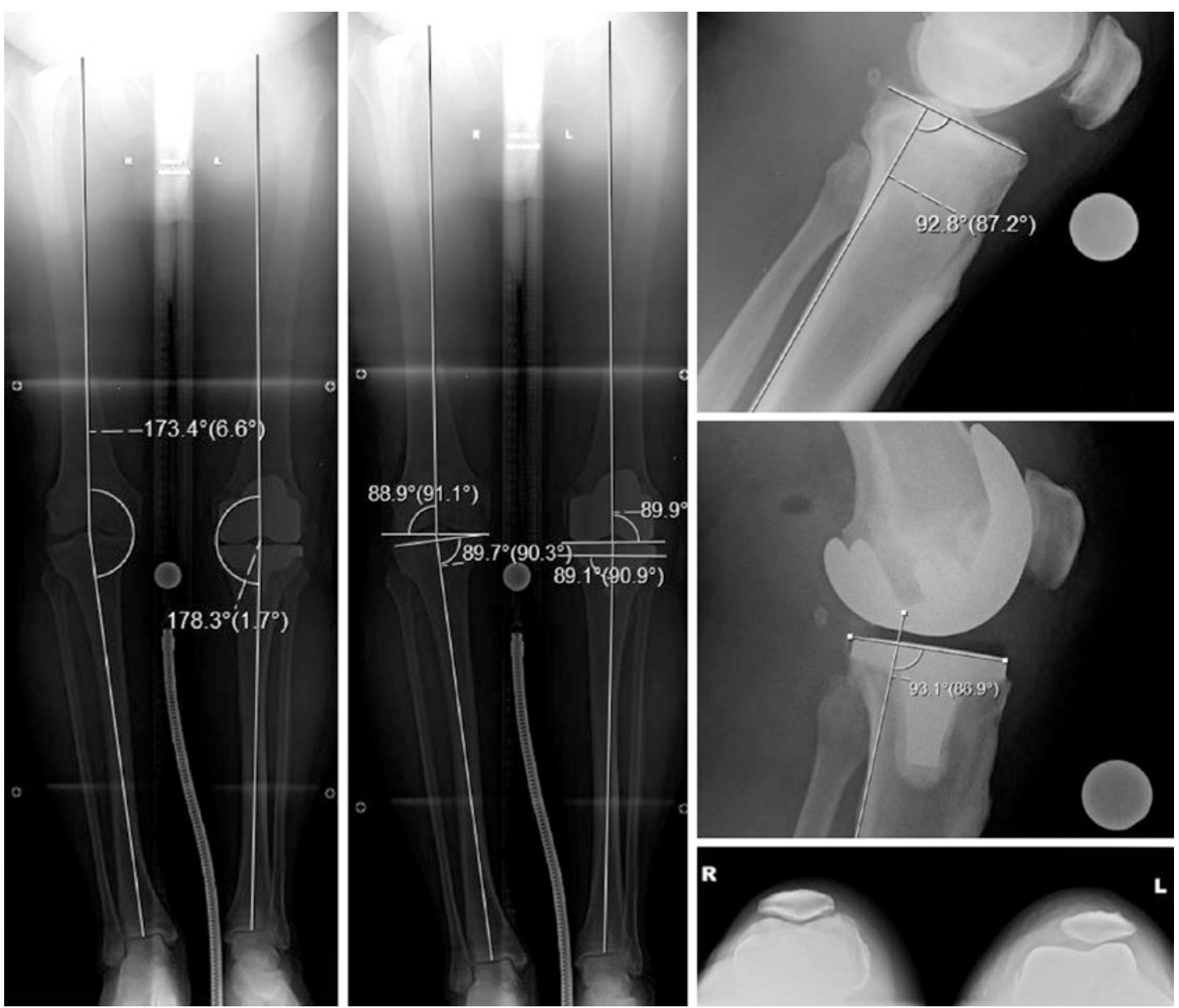

$\mathbf{R}$

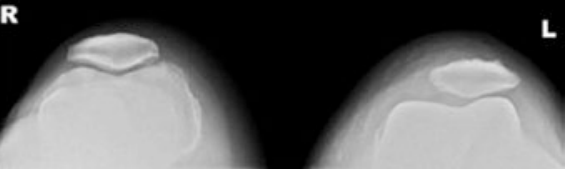

Fig. 16.16 Limb and knee radiographs. Post-operative long-leg radiographs with measurment of limb alignment (left long-leg radiograph) and components alignment relative to the femoral and tibial mechanical axis (right longleg radiograph) suggesting adequat restoration of the constitutional frontal limb and knee alignment. Pre- and post-operative lateral knee radiographs confirming the adequat restoration of the individual tibia slope. Postoperative skyline view showing slight lateral patella shift at early knee flexion

At 6 months follow-up, the patient was painfree with an Oxford Knee Score at 42 and a satisfaction at 95/100.

\section{References}

1. Howell SM, Hull ML. Kinematically aligned TKA with MRI-based cutting guides. In: Thienpont E, editor. Improving accuracy in knee arthroplasty. New Delhi: Jaypee Brothers Medical Publishers (P) Ltd; 2012. p. 207-32.

2. Eckhoff DG. Three-dimensional mechanics, kinematics, and morphology of the knee viewed in virtual reality. J Bone Jt Surg Am. 2005;87(suppl_2):71. 
3. Iranpour F, Merican AM, Dandachli W, et al. The geometry of the trochlear groove. Clin Orthop Relat Res. 2010;468(3):782-8.

4. Yin L, Chen K, Guo L, et al. Identifying the functional flexion-extension axis of the knee: an in-vivo kinematics study. PLoS One. 2015;10(6):e0128877.

5. Rivière C, Iranpour F, Auvinet E, et al. Alignment options for total knee arthroplasty: a systematic review. Orthop Traumatol Surg Res. 2017;103(7):1047-56.

6. Nam D, Nunley RM, Barrack RL. Patient dissatisfaction following total knee replacement: a growing concern? Bone Jt J. 2014;96-B(11_Supple_A):96-100.

7. Meehan JP, Danielsen B, Kim SH, et al. Younger age is associated with a higher risk of early periprosthetic joint infection and aseptic mechanical failure after total knee arthroplasty. J Bone Jt Surg Am. 2014;96(7):529-35.

8. Price AJ, Alvand A, Troelsen A, Katz JN, Hooper G, Gray A, et al. Knee replacement. Lancet. 2018;392(10158):1672-82.

9. Le DH, Goodman SB, Maloney WJ, Huddleston JI. Current modes of failure in TKA: infection, instability, and stiffness predominate. Clin Orthop Relat Res. 2014;472(7):2197-200.

10. Song SJ, Detch RC, Maloney WJ, Goodman SB, Huddleston JI. Causes of instability after total knee arthroplasty. J Arthroplast. 2014;29(2):360-4.

11. Rivière $\mathrm{C}$, Iranpour $\mathrm{F}$, Auvinet $\mathrm{E}$, et al. Mechanical alignment technique for TKA: are there intrinsic technical limitations? Orthop Traumatol Surg Res. 2017;103(7):1057-67.

12. Gu Y, Roth JD, Howell SM, Hull ML. How frequently do four methods for mechanically aligning a total knee arthroplasty cause collateral ligament imbalance and change alignment from normal in white patients? J Bone Jt Surg Am. 2014;96(12):e101-19.

13. Barrack RL, Schrader T, Bertot AJ, et al. Component rotation and anterior knee pain after total knee arthroplasty. Clin Orthop. 2001;392:46-55.

14. Bellemans J, Colyn W, Vandenneucker H, et al. The Chitranjan Ranawat Award: is neutral mechanical alignment normal for all patients?: The concept of constitutional varus. Clin Orthop Relat Res. 2012;470(1):45-53.

15. Roth JD, Howell SM, Hull ML. Native knee laxities at $0^{\circ}, 45^{\circ}$, and $90^{\circ}$ of flexion and their relationship to the goal of the gap-balancing alignment method of total knee arthroplasty. J Bone Jt Surg Am. 2015;97(20):1678-84.

16. Stoddard JE, Deehan DJ, Bull AMJ, et al. No difference in patellar tracking between symmetrical and asymmetrical femoral component designs in TKA. Knee Surg Sports Traumatol Arthrosc. 2014;22(3):534-42.

17. McClelland JA, Webster KE, Feller JA, et al. Knee kinematics during walking at different speeds in people who have undergone total knee replacement. Knee. 2011;18(3):151-5.

18. Fitzpatrick CK, Rullkoetter PJ. Influence of patellofemoral articular geometry and material on mechanics of the unresurfaced patella. J Biomech. 2012;45(11):1909-15.

19. Eckhoff DG, Jacofsky DJ, Springer BD, et al. Bilateral symmetrical comparison of femoral and tibial anatomic features. J Arthroplast. 2016;31(5):1083-90.

20. Deep K. Collateral ligament laxity in knees: what is normal? Clin Orthop Relat Res. 2014;472(11):3426-31.

21. Bonner TJ, Eardley WGP, Patterson P, et al. The effect of post-operative mechanical axis alignment on the survival of primary total knee replacements after a follow-up of 15 years. J Bone Joint Surg Br. 2011;93-B(9):1217-22.

22. Abdel MP, Ollivier M, Parratte S, et al. Effect of postoperative mechanical axis alignment on survival and functional outcomes of modern total knee arthroplasties with cement: a concise follow-up at 20 years. J Bone Jt Surg. 2018;100(6):472-8.

23. Deep K, Eachempati KK, Apsingi S. The dynamic nature of alignment and variations in normal knees. Bone Jt J. 2015;97-B(4):498-502.

24. Rivière C, Ollivier M, Girerd D, et al. Does standing limb alignment after total knee arthroplasty predict dynamic alignment and knee loading during gait? Knee. 2017;24(3):627-33.

25. Nagura T, Niki Y, Harato K, et al. Analysis of the factors that correlate with increased knee adduction moment during gait in the early postoperative period following total knee arthroplasty. Knee. 2017;24(2):250-7.

26. Kutzner I, Trepczynski A, Heller MO, et al. Knee adduction moment and medial contact forcefacts about their correlation during gait. PLoS One. 2013;8(12):e81036.

27. Nakano N, Matsumoto $T$, Muratsu $H$, et al. Postoperative knee flexion angle is affected by lateral laxity in cruciate-retaining total knee arthroplasty. J Arthroplast. 2016;31(2):401-5.

28. Takahashi T, Ansari J, Pandit H. Kinematically aligned total knee arthroplasty or mechanically aligned total knee arthroplasty. J Knee Surg. 2018;31(10):999-1006.

29. Shelton T, Howell S, Hull M. A total knee arthroplasty is stiffer when the intraoperative tibial force is greater than the native knee. J Knee Surg. 2019;32:1008-14.

30. Shelton TJ, Nedopil AJ, Howell SM, Hull ML. Do varus or valgus outliers have higher forces in the medial or lateral compartments than those which are in-range after a kinematically aligned total knee arthroplasty?: limb and joint line alignment after kinematically aligned total knee arthroplasty. Bone Jt J. 2017;99-B(10):1319-28.

31. Niki Y, Nagura T, Nagai K, et al. Kinematically aligned total knee arthroplasty reduces knee adduction moment more than mechanically aligned total knee arthroplasty. Knee Surg Sports Traumatol Arthrosc. 2018;26(6):1629-35.

32. Blakeney W, Clément J, Desmeules F, et al. Kinematic alignment in total knee arthroplasty better reproduces normal gait than mechanical alignment. In: Knee Surg Sports Traumatol Arthrosc, vol. 27; 2019. p. 1410-7. 
33. Keshmiri A, Maderbacher G, Baier C, et al. Kinematic alignment in total knee arthroplasty leads to a better restoration of patellar kinematics compared to mechanic alignment. In: Knee Surg Sports Traumatol Arthrosc, vol. 27; 2019. p. 1529-34.

34. Koh IJ, Park IJ, Lin CC, et al. Kinematically aligned total knee arthroplasty reproduces native patellofemoral biomechanics during deep knee flexion. In: Knee Surg Sports Traumatol Arthrosc, vol. 27; 2019. p. $1520-8$.

35. Howell SM, Shelton TJ, Hull ML. Implant survival and function ten years after kinematically aligned total knee arthroplasty. J Arthroplast. 2018;33:3678-84.

36. Nedopil AJ, Howell SM, Hull ML. What clinical characteristics and radiographic parameters are associated with patellofemoral instability after kinematically aligned total knee arthroplasty? Int Orthop. 2017;41(2):283-91.

37. Hutt JRB, LeBlanc M-A, Massé V, et al. Kinematic TKA using navigation: surgical technique and initial results. Orthop Traumatol Surg Res. 2016;102(1):99-104.

38. Almaawi AM, Hutt JRB, Masse V, et al. The impact of mechanical and restricted kinematic alignment on knee anatomy in total knee arthroplasty. J Arthroplast. 2017;32(7):2133-40.

39. Young SW, Walker ML, Bayan A, et al. The Chitranjan S. Ranawat Award: no difference in 2-year functional outcomes using kinematic versus mechanical alignment in TKA: a randomized controlled clinical trial. Clin Orthop Relat Res. 2017;475(1):9-20.

40. Waterson HB, Clement ND, Eyres KS, et al. The early outcome of kinematic versus mechanical alignment in total knee arthroplasty: a prospective randomised control trial. Bone Jt J. 2016;98-B(10):1360-8.

41. Calliess T, Bauer K, Stukenborg-Colsman C, et al. PSI kinematic versus non-PSI mechanical alignment in total knee arthroplasty: a prospective, randomized study. Knee Surg Sports Traumatol Arthrosc. 2017;25(6):1743-8.

42. Dossett HG, Estrada NA, Swartz GJ, et al. A randomised controlled trial of kinematically and mechanically aligned total knee replacements: Twoyear clinical results. Bone Jt J. 2014;96-B(7):907-13.

43. Niki Y, Kobayashi S, Nagura $T$, et al. Joint line modification in kinematically aligned total knee arthroplasty improves functional activity but not patient satisfaction. J Arthroplast. 2018;33(7):2125-30.

44. Fitch DA, Sedacki K, Yang Y. Mid- to long-term outcomes of a medial-pivot system for primary total knee replacement: a systematic review and meta-analysis. Bone Jt Res. 2014;3(10):297-304.

45. Howell SM, Papadopoulos S, Kuznik KT, et al. Accurate alignment and high function after kinematically aligned TKA performed with generic instruments. Knee Surg Sports Traumatol Arthrosc. 2013;21(10):2271-80.
46. Nedopil AJ, Singh AK, Howell SM, et al. Does calipered kinematically aligned TKA restore native left to right symmetry of the lower limb and improve function? J Arthroplast. 2018;33(2):398-406.

47. Calliess T, Karkosh R, Windhagen H, et al. Concept of a femur-first-extension-gap-balancer for optimized manual kinematic alignment in total knee arthroplasty. Poster ESSKA Academy 2018.

48. Hutt J, Massé V, Lavigne M, et al. Functional joint line obliquity after kinematic total knee arthroplasty. Int Orthop. 2016;40(1):29-34.

49. Rivière $C$, Iranpour $F$, Harris $S$, et al. The kinematic alignment technique for TKA reliably aligns the femoral component with the cylindrical axis. Orthop Traumatol Surg Res. 2017;103(7):1069-73.

50. Nedopil AJ, Howell SM, Rudert M, et al. How frequent is rotational mismatch within $0^{\circ} \pm 10^{\circ}$ in kinematically aligned total knee arthroplasty? Orthopedics. 2013;36(12):e1515-20.

51. Rivière C, Dhaif F, Shah H, et al. Kinematic alignment of current TKA implants does not restore the native trochlear anatomy. Orthop Traumatol Surg Res. 2018;104(7):983-95.

52. Rivière $\mathrm{C}$, Iranpour $\mathrm{F}$, Harris $\mathrm{S}$, et al. Differences in trochlear parameters between native and prosthetic kinematically or mechanically aligned knees. Orthop Traumatol Surg Res. 2018;104(2):165-70.

53. Dossett HG, Swartz GJ, Estrada NA, et al. Kinematically versus mechanically aligned total knee arthroplasty. Orthopedics. 2012;35:e160-9.

54. Rivière C, Lazic S, Villet L, et al. Kinematic alignment technique for total hip and knee arthroplasty: the personalized implant positioning surgery. EFORT Open Rev. 2018;3(3):98-105.

55. Ng CK, Chen JY, Yeh JZY, et al. Distal femoral rotation correlates with proximal tibial joint line obliquity: a consideration for kinematic total knee arthroplasty. J Arthroplast. 2018;33(6):1936-44.

56. Brar AS, Howell SM, Hull ML. What are the bias, imprecision, and limits of agreement for finding the flexion-extension plane of the knee with five tibial reference lines? Knee. 2016;23(3):406-11.

57. Nam D, Lin KM, Howell SM, et al. Femoral bone and cartilage wear is predictable at $0^{\circ}$ and $90^{\circ}$ in the osteoarthritic knee treated with total knee arthroplasty. Knee Surg Sports Traumatol Arthrosc. 2014;22(12):2975-81.

58. Matsumoto T, Takayama K, Ishida $\mathrm{K}$, et al. Radiological and clinical comparison of kinematically versus mechanically aligned total knee arthroplasty. Bone Jt J. 2017;99-B(5):640-6.

59. Dossett HG, et al. Kinematically versus mechanically aligned total knee arthroplasty. Orthopedics. 2012;35(2):e160-9.

60. Woon JTK, Zeng ISL, Calliess T, et al. Outcome of kinematic alignment using patient-specific instrumentation versus mechanical alignment in 
TKA: a meta-analysis and subgroup analysis of randomised trials. Arch Orthop Trauma Surg. 2018;138(9):1293-303.

61. Courtney PM, Lee G-C. Early outcomes of kinematic alignment in primary total knee arthroplasty: a meta-analysis of the literature. J Arthroplast. 2017;32(6):2028-2032.e1.

62. McNair PJ, Boocock MG, Dominick ND, et al. A comparison of walking gait following mechanical and kinematic alignment in total knee joint replacement. J Arthroplast. 2018;33(2):560-4.

63. Ji H-M, Han J, Jin DS, Seo H, Won Y-Y. Kinematically aligned TKA can align knee joint line to horizontal. Knee Surg Sports Traumatol Arthrosc. 2016;24(8):2436-41.

64. Lozano R, Campanelli V, Howell S, Hull M. Kinematic alignment more closely restores the groove location and the sulcus angle of the native trochlea than mechanical alignment: implications for prosthetic design. Knee Surg Sports Traumatol Arthrosc. 2019;27:1504-13.

65. Maillot C, Riviere C, Ciara H. Poor relationship between frontal tibiofemoral and trochlear anatomic parameters: implications for designing new knee implants for kinematic alignment. Knee. 2019;26:106-14.

Open Access This chapter is licensed under the terms of the Creative Commons Attribution 4.0 International License (http://creativecommons.org/licenses/by/4.0/), which permits use, sharing, adaptation, distribution and reproduction in any medium or format, as long as you give appropriate credit to the original author(s) and the source, provide a link to the Creative Commons license and indicate if changes were made.

The images or other third party material in this chapter are included in the chapter's Creative Commons license, unless indicated otherwise in a credit line to the material. If material is not included in the chapter's Creative Commons license and your intended use is not permitted by statutory regulation or exceeds the permitted use, you will need to obtain permission directly from the copyright holder. 